\title{
Effects of human relaxin-2 (serelaxin) on hypoxic pulmonary vasoconstriction during acute hypoxia in a sheep model
}

This article was published in the following Dove Press journal: Hypoxia

\author{
René Schiffner ${ }^{1,2}$ \\ Marius Nistor ${ }^{2}$ \\ Sabine Juliane Bischoff ${ }^{3}$ \\ Georg Matziolis' \\ Martin Schmidt ${ }^{4}$ \\ Thomas Lehmann ${ }^{5}$ \\ 'Orthopaedic Department, \\ ${ }^{2}$ Department of Neurology, ${ }^{3}$ Central \\ Animal Facility, ${ }^{4}$ Institute for \\ Biochemistry II, ${ }^{5}$ Institute of Medical \\ Statistics, Computer Sciences \\ and Documentation Science, Jena \\ University Hospital, Friedrich Schiller \\ University, Jena, Germany
}

Purpose: Hypoxia induces pulmonary vasoconstriction with a subsequent increase of pulmonary artery pressure (PAP), which can result in pulmonary hypertension. Serelaxin has shown an increase of pulmonary hemodynamic parameters after serelaxin injection. We therefore investigated the response of pulmonary hemodynamic parameters after serelaxin administration in a clinically relevant model.

Methods: Six controls and six sheep that received $30 \mu \mathrm{g} / \mathrm{kg}$ serelaxin underwent right heart catheterization during a 12-minute hypoxia period (inhalation of $5 \%$ oxygen and $95 \%$ nitrogen) and subsequent reoxygenation. Systolic, diastolic, and mean values of both PAP (respectively, PAPs, PAPd, and PAPm) and pulmonary capillary wedge pressure (respectively, PCWPs, PCWPd, and PCWPm), blood gases, heart rate (HR), and both peripheral and pulmonary arterial oxygen saturation were obtained. Cardiac output (CO), stroke volume (SV), pulmonary vascular resistance (PVR), pulmonary arterial compliance (PAcompl), and systemic vascular resistance (SVR) were calculated.

Results: The key findings of the current study are that serelaxin prevents the rise of PAPs $(p \leq 0.001)$, PAPm, PCWPm, PCWPs $(p \leq 0.03)$, and PAPd $(p \leq 0.05)$ during hypoxia, while it simultaneously increases CO and SV $(p \leq 0.001)$. Similar courses of decreases of PAPm, PAPd, PAPs, CO, SVR ( $p \leq 0.001)$, and PCWPd $(p \leq 0.03)$ as compared to hypoxic values were observed during reoxygenation. In direct comparison, the experimental groups differed during hypoxia in regard to HR, PAPm, PVR, and SVR $(p \leq 0.03)$, and during reoxygenation in regard to HR $(p \leq 0.001)$, PAPm, PAPs, PAPd, PVR, SVR $(p \leq 0.03)$, and PCWPd $(p \leq 0.05)$.

Conclusion: The findings of this study suggest that serelaxin treatment improves pulmonary hemodynamic parameters during acute hypoxia.

Keywords: hypoxic pulmonary vasoconstriction, pulmonary hemodynamics, relaxin-2, hypoxia, serelaxin, right heart catheterization

\section{Introduction}

During states of hypoxia, pulmonary circulation undergoes several changes and thereby deviates from systemic circulation. While lack of oxygen has direct vasodilating effects on systemic arterioles, it constitutes the most important vasoconstricting trigger acting on the pulmonary arterioles. ${ }^{1}$ These physiologic response mechanisms account for the underlying pathogenic reasons for the development of pulmonary hypertension as well. ${ }^{2-5}$ Intermittent hypoxia results in an increase of pulmonary artery pressure (PAP) and alters the general pulmonary hemodynamic physiology, for example by reducing pulmonary arterial compliance (PAcompl), increasing pulmonary vascular resistance (PVR) and systemic vascular resistance (SVR), and decreasing cardiac output (CO), as
Orthopaedic Department, Jena University Hospital, Friedrich Schiller University, Campus Eisenberg, Klosterlausnitzer Straße 8I, D-07607 Eisenberg, Germany Tel +493669l8 I292

Fax +493669181029

Email rene.schiffner@med.uni-jena.de 
reported in various animal and human studies..$^{6-14}$ Pulmonary vasoconstriction, with its subsequent pulmonary hemodynamic alterations, is a contributing factor in the development of heart failure. ${ }^{15}$

The therapeutic administration of a recombinant form of human relaxin-2 (serelaxin; Novartis Pharma, Basel, Switzerland) is still controversially discussed. ${ }^{16-18}$ In the RELAX-AHF study, cardiovascular and all-cause mortality were reduced $37 \%$ in patients treated with serelaxin. ${ }^{16}$ The follow-up study RELAX-AHF 2 failed to substantiate these results. ${ }^{18}$ Complete data of the RELAX-AHF 2 study are not available currently. Relaxin- 2 modulates the endothelial vasodilatory function in humans; the same effects are inducible in nonpregnant animals as well. ${ }^{19,20}$

Serelaxin furthermore increases arterial compliance and improves pulmonary hemodynamics. ${ }^{21-23}$ Its positive influences on pulmonary hemodynamics have already been shown in patients with pulmonary hypertension. ${ }^{15}$ Nonetheless, specific responses of hemodynamic parameters during states of hypoxia after serelaxin administration have not been investigated so far. An examination of the effects of serelaxin under this specific condition seems necessary though, since it is conceivable that serelaxin could constitute a negative influence in these situations. Since serelaxin triggers an endothelial modulation with a subsequent vasodilation, cardiopulmonary instability appears possible in cases of severe clinical situations, for example hypoxia.

\section{Materials and methods}

\section{Animal care, surgical instrumentation,} anesthesia, and experimental protocol

Approval for the experiment was obtained from the Thuringia Animal Welfare Committee, (Bad Langensalza; permission number TVV 02-056/13 valid from December 13, 2013 until December 20,2016) and all procedures were conducted in conformity with the Animal Welfare Act, and the ARRIVE guidelines $^{82}$ were followed. Twelve 2-6 year old female, nonpregnant Merino long wool sheep, weighing 84.7 \pm 6.2 $\mathrm{kg}$, underwent surgery in accordance with the Guide for the Care and Use of Laboratory Animals. ${ }^{24}$ We have previously described the surgical instrumentation, anesthesia, data recording, and blood gas measurements in detail. ${ }^{25}$ Briefly, after food withdrawal for 24 hours, anesthesia was induced by intramuscular injection of ketamine and was maintained via inhalation of $1.5 \%$ isoflurane over the course of the entire experiment. In a left lateral position, vascular catheters were inserted into the carotid artery (for blood sampling, blood pressure measurement), the left jugular vein (for intraoperative administration of analgesics), and the right jugular vein with a Swan-Ganz catheter (for blood sampling and assessment of pulmonary hemodynamics in the pulmonary artery). The right heart data acquisition was continuously performed and has been described previously. ${ }^{26}$ We used a heart catheter station (evoelement ${ }^{\circledR}$; Schwarzer, Heilbronn, Germany) for data recording and to analyze the primary data in connection to time points (eg, heart rate [HR], PAP, pulmonary capillary wedge pressure [PCWP]).

Subsequent to 10 minutes of baseline recordings, during oxygenation ensued with $50 \%$ oxygen, six sheep (control group) received a bolus injection of $20 \mathrm{~mL}$ saline (Isotonische Kochsalzlösung ${ }^{\circledR}$; Fresenius, Bad Homburg, Germany) and six sheep (serelaxin-treated group) received an injection of $30 \mu \mathrm{g} / \mathrm{kg}$ serelaxin $(0.1-0.15 \mathrm{~mL}$ stock solution) diluted in saline (serelaxin).

\section{Experimental protocol of hypoxia}

Hypoxia was induced by inhalation of 5\% oxygen and $95 \%$ nitrogen and was maintained for 12 minutes; subsequently, reoxygenation ensued with $50 \%$ oxygen over 20 minutes under constant monitoring of breathing and heart frequency, blood pressure, blood gas concentrations, body temperature, oxygen saturation, and shock index values.

\section{Pulmonary hemodynamics}

During the right heart catheterization, the systolic, diastolic, and mean PAP (PAPs, PAPd, and PAPm), systolic, diastolic, and mean pulmonary capillary wedge pressure (PCWPs, PCWPd, and PCWPm), blood gases, and HR were recorded as described previously. ${ }^{26} \mathrm{CO}$ was calculated with Fick's method, ${ }^{27}$ PVR was calculated as (PAPm - PCWPm)/CO. ${ }^{28}$ SVR was calculated as mean arterial blood pressure (MABP)/ $\mathrm{CO}$, the stroke volume ( $\mathrm{SV}$ ) was calculated as $\mathrm{CO} / \mathrm{HR}$, and PAcompl was calculated as (PAPs - PAPd)/SV. ${ }^{28}$

\section{Statistical analysis}

Linear mixed regression models were fitted to compare the trend of pulmonary hemodynamic parameters between both groups. This approach allows accounting for the correlation of the repeated measurements of an animal. Independent variables of the models are group (serelaxin/control) and time of measurement, as well as their interaction. For each condition (hypoxia, no hypoxia), a separate model was calculated. Regression coefficients of the models were presented to describe the average change of pulmonary hemodynamic parameters per minute. The significance level was set to $\alpha=0.05$. All statistical analyses were performed with SPSS 
22.0 (IBM Corporation, Armonk, NY, USA). Data are given as mean differences \pm standard error of means or describe a trend over the time of each represented variable per minute. As some data sets were normally distributed all quantitations are presented as box plots, where boxes represent the 25 th and 75th percentiles, respectively. Medians are indicated by horizontal lines. Whiskers indicate 10th and 90th percentiles, respectively.

\section{Results}

\section{Blood parameters and vital parameters under serelaxin treatment during hypoxia and reoxygenation}

Arterial blood gases and lactate were within their physiological ranges before the onset of controlled hypoxia with subsequent reoxygenation (Table 1). Hypoxia induced a decrease of $\mathrm{pH}$ and $\mathrm{pO}_{2}$, and an increase of lactate $(p<0.05$, Table 1). Reoxygenation normalized $\mathrm{pH}$ and $\mathrm{pCO}_{2}$, and $\mathrm{pO}_{2}$ was restored to baseline. No differences were observed between the control and the serelaxin-treated group.

During hypoxia, no significant changes of the MABP were observed over time and between the groups. During reoxygenation, the serelaxin-treated group exhibited slightly decreased MABP values directly after the hypoxic episode $(p=0.015)$; nonetheless, no significant differences were observed between the groups (Figure 1A).

During the hypoxic intervention, the HR was significantly lower in the control group than in the serelaxin-treated group (mean difference $=48.4$ beats per minute $[\mathrm{bpm}], p=0.015$ ). On average, hypoxia significantly increased the HR by $2.9 \mathrm{bpm}$ in the serelaxin-treated group $(p<0.001)$. During reoxygenation, the HR values of the control group were again significantly lower than in the serelaxin-treated group (mean difference
$=65.9 \mathrm{bpm}, p<0.001)$. On average, reoxygenation significantly decreased the HR by $2.4 \mathrm{bpm}$ in the serelaxin-treated group $(p<0.001)$, as compared to the HR values measured at the end of the hypoxic episode. No significant changes of the HR were observed over time during hypoxia and reoxygenation in the control group (Figure 1B).

The femoral arterial and pulmonary arterial oxygen saturation exhibited similar courses of decreases in both groups over the course of the hypoxia, and thereafter similar courses of increases under reoxygenation in both groups $(p<0.001)$ (Figure 2A, B).

\section{Effects of serelaxin on hemodynamic parameters and vascular resistance during hypoxia and reoxygenation}

Analysis of the PAP revealed significant differences regarding the development of the PAPm, PAPs, and PAPd during the observation period in the serelaxin-treated group as compared to the control group. No significant baseline differences exist between the groups. During hypoxia, PAPm was significantly lower in the serelaxin-treated group than in the control group (mean difference $=14.1 \mathrm{mmHg}, p=0.019$ ). On average, PAPm significantly increased by $0.6 \mathrm{mmHg}$ per minute during hypoxia in the control group $(p=0.002)$. During reoxygenation, PAPm remained significantly higher in the control group than in the serelaxin-treated group (mean difference $=11.6 \mathrm{mmHg}, p=0.003$ ). During reoxygenation, the PAPm significantly decreased by $0.8 \mathrm{mmHg}$ per minute in the control group $(p<0.001)$ and $0.3 \mathrm{mmHg}$ per minute in the serelaxin-treated group ( $p=0.001)$ (Figure 3A). The PAPs of the control group significantly increased by $0.9 \mathrm{mmHg}$ per minute during hypoxia $(p=0.001)$. During reoxygenation, PAPs remained significantly lower in the serelaxin-treated

Table I Blood parameters during hypoxia

\begin{tabular}{|c|c|c|c|c|c|c|c|c|}
\hline & \multicolumn{8}{|c|}{ Blood parameters } \\
\hline & \multicolumn{4}{|c|}{ Control group } & \multicolumn{4}{|c|}{ Serelaxin-treated group } \\
\hline & Basal & $\begin{array}{l}\text { I-min } \\
\text { hypoxia }\end{array}$ & $\begin{array}{l}\text { I2-min } \\
\text { hypoxia }\end{array}$ & $\begin{array}{l}20 \text { min after } \\
\text { reoxygenation }\end{array}$ & Basal & $\begin{array}{l}\text { I-min } \\
\text { hypoxia }\end{array}$ & $\begin{array}{l}\text { I 2-min } \\
\text { hypoxia }\end{array}$ & $\begin{array}{l}20 \text { min after } \\
\text { reoxygenation }\end{array}$ \\
\hline $\mathrm{pH}$ & $7.4( \pm 0.08)$ & $7.37( \pm 0.13)$ & $7.33^{*}( \pm 0.04)$ & $7.3( \pm 0.16)$ & $7.4( \pm 0.06)$ & $7.43( \pm 0.05)$ & $7.32 *( \pm 0.09)$ & $7.37( \pm 0.04)$ \\
\hline $\mathrm{PCO}_{2}(\mathrm{kPa})$ & $6( \pm 0.9)$ & $6.6( \pm 0.4)$ & $5.9( \pm 0.8)$ & $6.2( \pm 0.9)$ & $5.7( \pm I . I)$ & $5.7( \pm 0.9)$ & $4.9( \pm 0.3)$ & $6.1( \pm 0.6)$ \\
\hline $\mathrm{pO}_{2}(\mathrm{kPa})$ & $10.2( \pm 2.6)$ & $12.3( \pm 2.8)$ & $2.8^{*}( \pm 0.5)$ & $12.1( \pm 3)$ & $10.8( \pm 1.8)$ & $13.4( \pm 3.3)$ & $2.7^{*}( \pm 0.3)$ & $10.6( \pm 1.6)$ \\
\hline Lactate (mmol/L) & $2.2( \pm 0.7)$ & $1.7( \pm 0.4)$ & $4.7^{*}( \pm 1.0)$ & $3.5( \pm 0.7)$ & $2.9( \pm 2)$ & $1.9( \pm I)$ & $6.1 *( \pm 1.3)$ & $3.1( \pm 1.8)$ \\
\hline Glucose (mmol/L) & $3.5( \pm 1.2)$ & $3.4( \pm 0.9)$ & $6.9( \pm 2.4)$ & $8.4( \pm 3.2)$ & $3.2( \pm 0.8)$ & $3.2( \pm 0.7)$ & $4.6( \pm I)$ & $4.9( \pm 1.9)$ \\
\hline $\mathrm{BE}(\mathrm{mmol} / \mathrm{L})$ & $3( \pm 2.6)$ & $3.7( \pm 2.6)$ & $2.9( \pm 1.7)$ & $0( \pm 3)$ & $2.4( \pm 4.7)$ & $3.7( \pm 3.9)$ & $3.7( \pm 2.1)$ & $2( \pm 3)$ \\
\hline
\end{tabular}

Notes: Changes of blood parameters are listed. Blood samples were drawn from the arteria femoralis. Samples were taken at baseline (basal), immediately during I-min hypoxia, during 12-min hypoxia, or $20 \mathrm{~min}$ after reoxygenation (total $40 \mathrm{~min}$ ). All data are given as mean $\pm \mathrm{SD},{ }^{*} p<0.05$.

Abbreviations: $\mathrm{pCO}_{2} / \mathrm{pO}_{2}$, partial pressure of carbon dioxide/oxygen; $\mathrm{BE}$, base excess. 

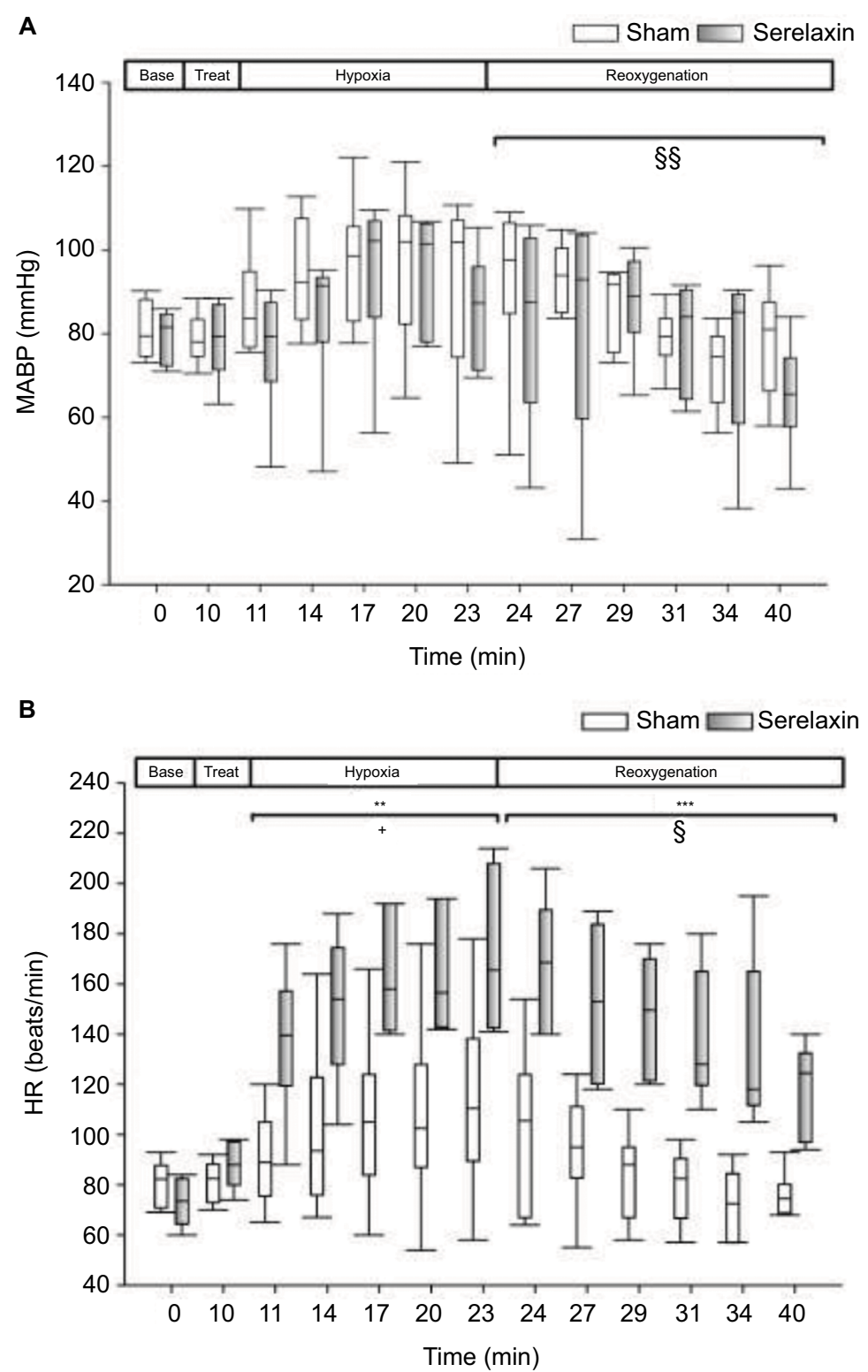

Figure I Effects of serelaxin during hypoxia and reoxygenation on mean arterial pressure and heart rate.

Notes: (A) MABP and (B) HR of the serelaxin-treated (gray symbols) or control group (sham, white symbols), respectively. ***, $p \leq 0.001$; **, $p \leq 0.03$, for comparison between the two experimental groups during hypoxia or reoxygenation, respectively.,$+ p \leq 0.05$, for comparison of the serelaxin-treated group during hypoxia with baseline values. $\S \S, p \leq 0.03 ; \S, p \leq 0.05$, for comparison of reoxygenation with hypoxia in the serelaxin-treated group.

Abbreviations: MABP, mean arterial blood pressure; HR, heart rate.

group as compared to the control group (mean difference $=12.6 \mathrm{mmHg}, p=0.018$ ); PAPs decreased by $1.2 \mathrm{mmHg}$ per minute in the control group $(p<0.001)$ and by $0.7 \mathrm{mmHg}$ per minute in the serelaxin-treated group $(p=0.014)$ over the course of the reoxygenation period as compared to the values measured at the end of the hypoxic period $(p<0.001)$ (Figure 3B). PAPd of the control group significantly increased by $0.5 \mathrm{mmHg}$ per minute during hypoxia $(p=0.044)$. PAPd of the serelaxin-treated group was significantly lower during the reoxygenation period as compared to the control group (mean difference $=11.4 \mathrm{mmHg}, p=0.005$ ) and decreased by $0.1 \mathrm{mmHg}$ per minute as compared to the values measured at the end of the hypoxic period $(p=0.001)$. PAPd in the control group decreased by $0.6 \mathrm{mmHg}$ per minute during reoxygenation compared to hypoxic values $(p<0.001)$ (Figure 3C).

Analysis of the PCWP values revealed a somewhat similar situation, with significant differences of PCWPm, PCWPs, and PCWPd between both groups over the course of the observation period. No significant baseline differences exist between the groups. During hypoxia, the PCWPm of the 

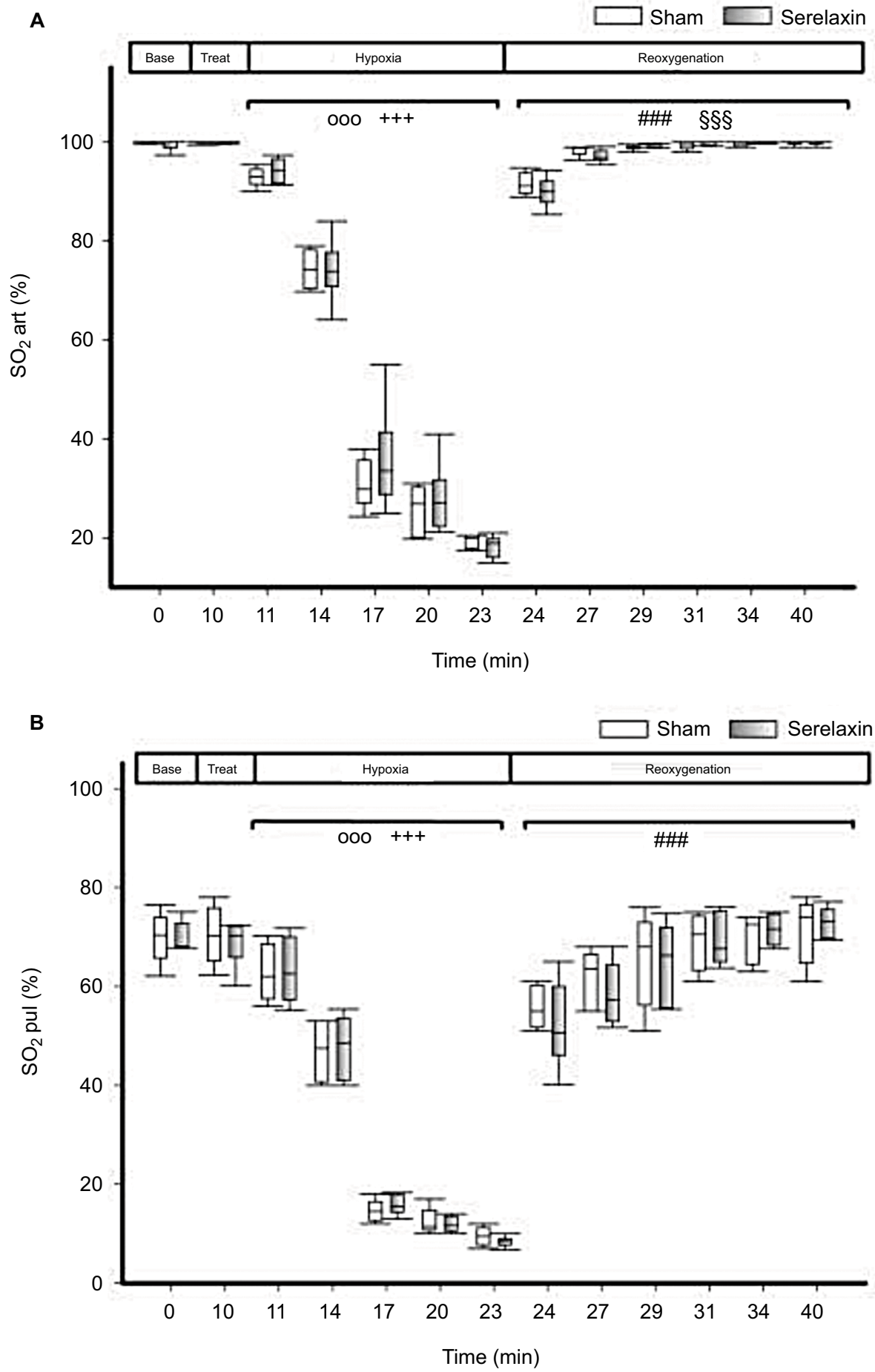

Figure 2 Effects of serelaxin during hypoxia and reoxygenation on arterial blood gases.

Notes: (A) $\mathrm{SO}_{2}$ art and (B) $\mathrm{SO}_{2}$ pul. ${ }^{\circ 00}, p \leq 0.00$ I, for comparison of the control group during hypoxia with baseline values.,$+++ p \leq 0.00 \mathrm{I}$, for comparison of the serelaxintreated group during hypoxia with baseline values. $\S \S \S, p \leq 0.00 \mathrm{I}$, for comparison of reoxygenation with hypoxia in the serelaxin-treated group. \#\#, $p \leq 0.00 \mathrm{I}$, for comparison of reoxygenation with hypoxia in the control group.

Abbreviations: $\mathrm{SO}_{2}$ art, femoral arterial oxygen saturation; $\mathrm{SO}_{2}$ pul, pulmonary arterial oxygen saturation.

control group significantly increased by $0.4 \mathrm{mmHg}$ per minute as compared to baseline ( $p=0.037)$. During reoxygenation, PCWPm decreased by $0.6 \mathrm{mmHg}$ per minute in the control group $(p<0.001)$ and by $0.2 \mathrm{mmHg}$ in the serelaxin-treated group ( $p=0.037$ ) as compared to hypoxic values (Figure $4 \mathrm{~A}$ ).
The PCWPs of the control group significantly increased by $0.7 \mathrm{mmHg}$ per minute during hypoxia $(p=0.005)$, and decreased by $0.8 \mathrm{mmHg}$ per minute $(p<0.001)$ during the reoxygenation; no significant changes were observed between the control group and the serelaxin-treated group (Figure 4B). 

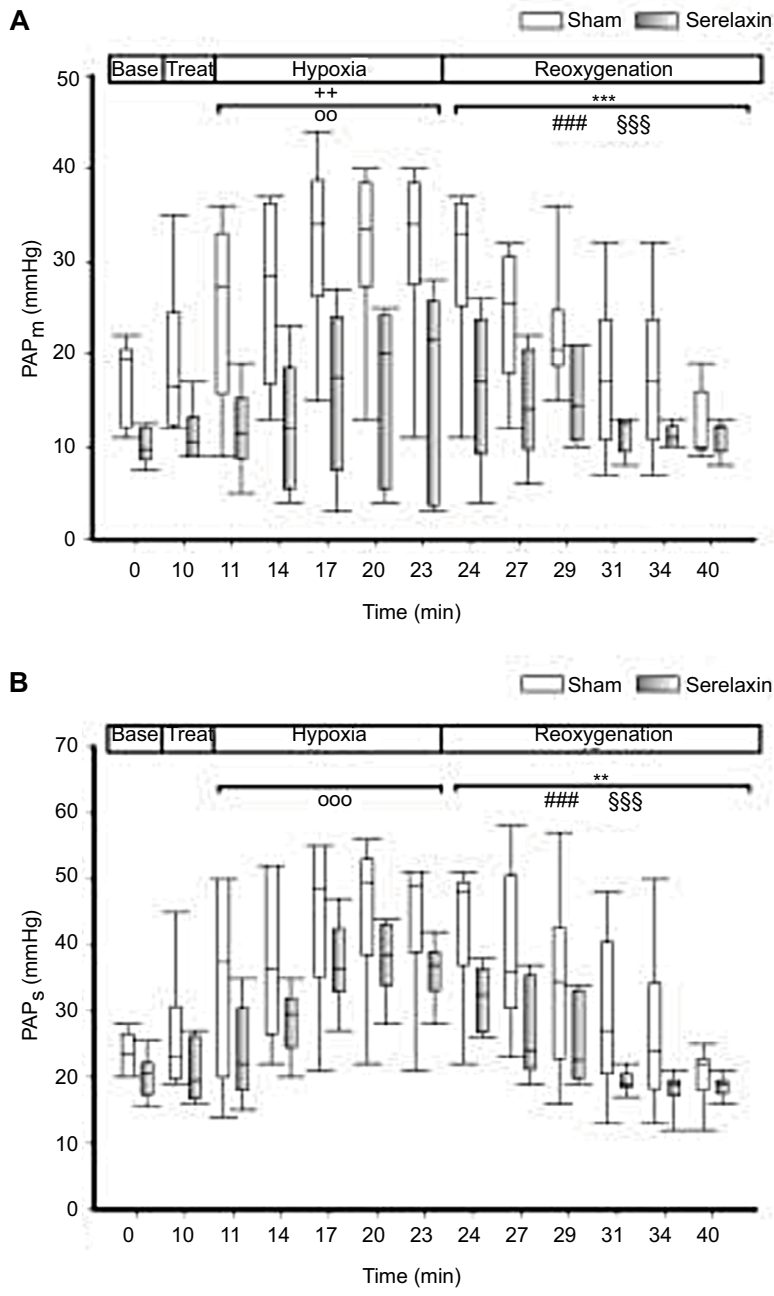

C

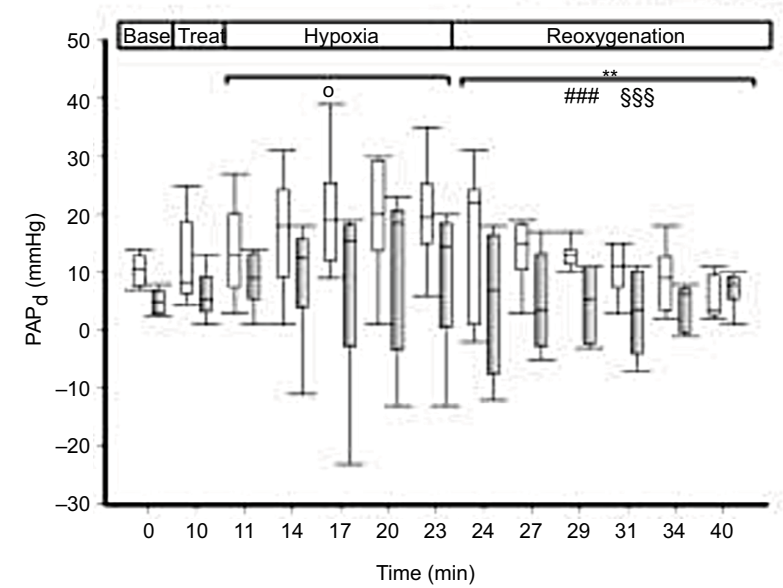

Figure 3 Effects of serelaxin during hypoxia and reoxygenation on pulmonary artery pressure.

Notes: (A) PAP $_{m}$, (B) PAP $_{s}$, and (C) PAP $_{\mathrm{d}^{*}} * *, p \leq 0.03$, for comparison between the two experimental groups during hypoxia or reoxygenation, respectively. ${ }^{000}$, $p \leq 0.00$ I; $^{\circ}, p \leq 0.03$; $^{\circ}, p \leq 0.05$, for comparison of the control group during hypoxia with baseline values. in the control group. $\S \S \S, p \leq 0.001 ; \S \S, p \leq 0.03$, for comparison of reoxygenation with hypoxia in the serelaxin-treated group.

Abbreviations: $\mathrm{PAP}_{m}$, mean pulmonary artery pressure; $\mathrm{PAP}_{s}$, systolic pulmonary artery pressure; PAP $_{\mathrm{d}}$, diastolic pulmonary artery pressure.
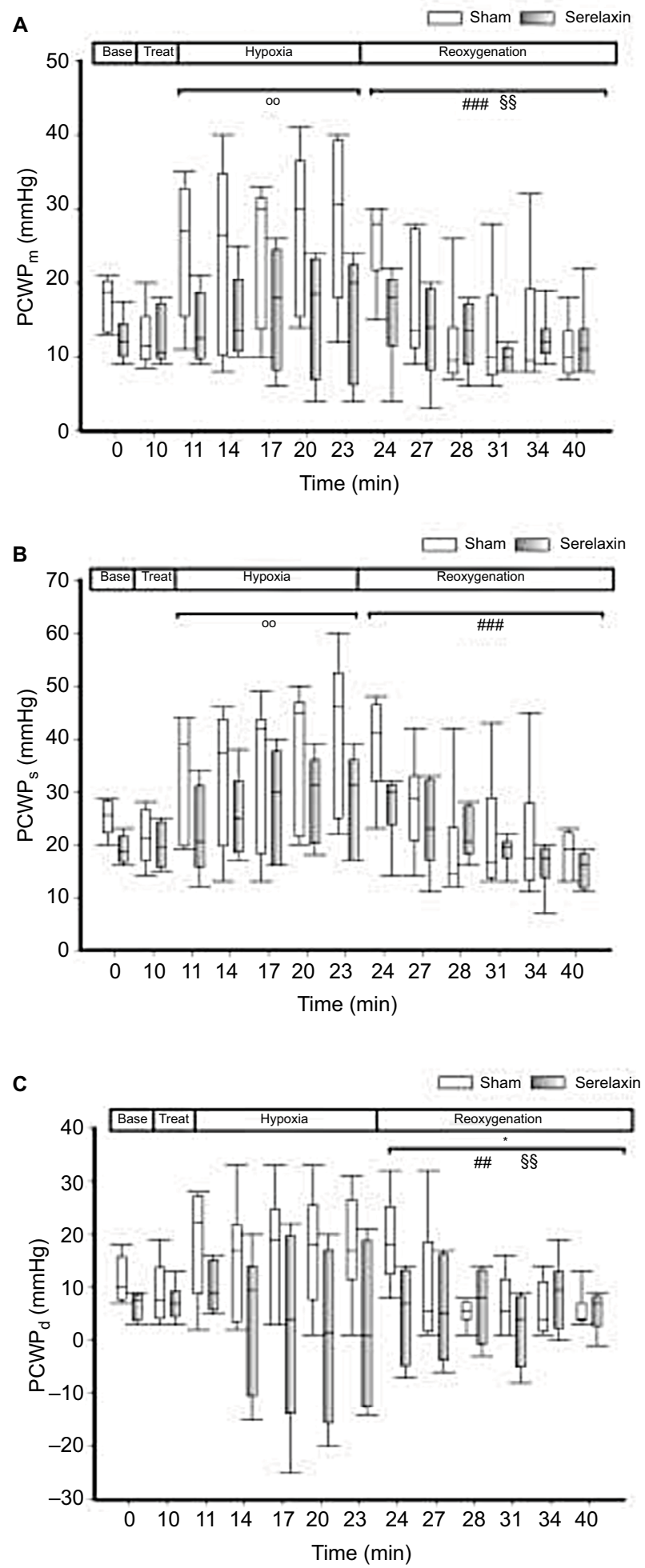

Figure 4 Effects of serelaxin during hypoxia and reoxygenation on pulmonary capillary wedge pressure.

Notes: (A) $\mathrm{PCWP}_{\mathrm{m}}$, (B) PCWP, and (C) $\mathrm{PCWP}_{\mathrm{d}}$. *, p $\leq 0.05$, for comparison between the two experimental groups during hypoxia or reoxygenation, respectively. ${ }^{\circ 0}, p \leq 0.03$, for comparison of the control group during hypoxia with baseline values. \#\#, $p \leq 0.001$; \#, $p \leq 0.03$, for comparison of reoxygenation with hypoxia in the control group. $\S \S, p \leq 0.03$, for comparison of reoxygenation with hypoxia in the serelaxin-treated group.

Abbreviations: $\mathrm{PCWP}_{\mathrm{m}}$, mean pulmonary capillary wedge pressure; $\mathrm{PCWP}_{\mathrm{s}}$, systolic pulmonary capillary wedge pressure; $\mathrm{PCWP}_{\mathrm{d}}$, diastolic pulmonary capillary wedge pressure. 
Regarding PCWPd, no significant changes could be observed between the groups during hypoxia; nonetheless, PCWPd of the serelaxin-treated group was significantly lower during the reoxygenation period as compared to the control group (mean difference $=7.3 \mathrm{mmHg}, p=0.049$ ), and increased by $0.1 \mathrm{mmHg}$ per minute as compared to the hypoxic episode ( $p=0.018$ ). PCWPd of the control group decreased by 0.5 $\mathrm{mmHg}$ per minute during reoxygenation, as compared to the hypoxic episode ( $p=0.003$ ) (Figure 4C).

Analysis of the $\mathrm{CO}$ revealed no significant differences between the groups over the course of hypoxia and reoxygenation. CO significantly increased by $0.2 \mathrm{~L}$ per minute in the serelaxin-treated group during hypoxia. It decreased in both groups during reoxygenation as compared to hypoxic values; in the serelaxin-treated group by $0.2 \mathrm{~L} / \mathrm{min}$ and in the control group by $0.1 \mathrm{~L} / \mathrm{min}(p<0.001)$ (Figure $5 \mathrm{~A})$. SV exhibited no significant differences between the groups over the course of hypoxia and reoxygenation. In the serelaxin-treated group, the SV significantly increased by $0.008 \mathrm{~L} /$ beat per minute during hypoxia $(p<0.001)$ and decreased by $0.003 \mathrm{~L} /$ beat per minute during reoxygenation $(p<0.001)$ (Figure $5 \mathrm{~B})$.

PVR of the serelaxin-treated group was significantly lower than that of the control group, both during hypoxia (mean difference $=0.5$ Wood's Unit [WU], $p=0.024$ ) and reoxygenation (mean difference $=0.8 \mathrm{WU}, p=0.005$ ). On average, in the serelaxin-treated group the PVR significantly decreased by $0.05 \mathrm{WU}$ per minute during reoxygenation as compared to hypoxic values $(p=0.005)$ (Figure 6A). SVR was significantly lower in the serelaxin-treated group as compared to the control group (mean difference $=1.5 \mathrm{mmHg}$ / [L/min], $p=0.002$ ), especially during reoxygenation (mean difference $=1.7 \mathrm{mmHg} /[\mathrm{L} / \mathrm{min}], p=0.004)$. On average, SVR significantly decreased by $0.1 \mathrm{mmHg} /(\mathrm{L} / \mathrm{min})$ in the serelaxin-treated group $(p=0.023)$, and by $0.2 \mathrm{mmHg} /(\mathrm{L} /$ $\mathrm{min})$ in the control group $(p<0.001)$ during hypoxia compared to baseline values (Figure 6B). During reoxygenation, the SVR significantly increased by $0.1 \mathrm{mmHg} /(\mathrm{L} / \mathrm{min})$ in the serelaxin-treated group ( $p=0.001)$, and by $0.2 \mathrm{mmHg} /(\mathrm{L} /$ min) in the control group $(p<0.001)$ as compared to hypoxic values (Figure 6B).

No differences between the PAcompl values of both groups could be observed during hypoxia. During reoxygenation, PAcompl of the serelaxin-treated group significantly decreased by $0.0003 \mathrm{~L} / \mathrm{mmHg}$ per minute $(p=0.021$ ) (Figure $6 \mathrm{C})$.

\section{Discussion}

The main new insights our experimental protocol revealed are that i) a decreased PAPm, ii) a decreased PVR, iii) and a decreased SVR can be observed in a sheep model of acute hypoxic vasoconstriction after a bolus injection of serelaxin.

Various studies have shown an increase of CO subsequent to serelaxin application, which has been described in experiments featuring relaxin-2 treatment in rats, ${ }^{29}$ sheep, ${ }^{26}$ and in acute heart failure patients with preserved left ventricular ejection fraction undergoing serelaxin treatment. ${ }^{15}$ Without the influence of medication though, $\mathrm{CO}$ and $\mathrm{SV}$ are known to remain unaltered under hypoxic conditions. ${ }^{30}$ Nevertheless, our results indicate that serelaxin quickly improves pulmonary hemodynamics, with no significant alterations of the global hemodynamics under hypoxic conditions. Furthermore, the results indicate that receptor-mediated changes occur regionally. Relaxin-2 is a very potent arterial vasodilator which exerts a rapid effect (within minutes) on the regional circulation in the brain and kidneys. ${ }^{31,32}$ Animal studies have already described systemic vasodilatory effects of relaxin-2, with a subsequent increase of vascular compliance and improvements of peripheral vasodilatation and atrial inotropy. ${ }^{19,26,33,34}$ The primary effect on inotropy has not been measured in this study. The positive chronotropic effects of relaxin-2 have been described previously. ${ }^{35}$ The positive influence of serelaxin on pulmonary hemodynamics in patients with pulmonary hypertension has already been shown in a study utilizing right heart catheterization procedures. ${ }^{15}$ The safe invasive procedure of right heart catheterization is the gold standard for hemodynamic assessments. ${ }^{36,37}$ Although a previous study has already provided evidence that serelaxin improves pulmonary hemodynamics in humans with pulmonary hypertension during a right heart catheterization, ${ }^{15}$ up to this point no study had been performed under acute hypoxic conditions. Our study provides evidence that similar positive effects can be observed under hypoxic conditions in a sheep model after serelaxin administration. Various studies have reveealed that hypoxic conditions result in an increase of PAP, PCWP, and an decrease of PVR, SVR. ${ }^{38-45}$ We utilized the large animal sheep model since its cardiovascular physiology is very similar to that of humans, which makes it a suitable model to investigate different conditions of the pulmonary vascular tree. ${ }^{46,47}$ These kinds of investigations necessitate a large animal model, since the otherwise oftentimes utilized rodent model is unsuitable due to the ability of rodents to adapt to low oxygen concentrations. ${ }^{1}$ The animals received a bolus injection of serelaxin equivalent to a daily human dose. ${ }^{48}$ This represents a consciously chosen high dosage, which would be administered over a period of 24 hours in humans. ${ }^{49}$ While this dose does therefore not represent actual serelaxin prescription schemes for heart failure, ${ }^{48}$ it ensured 


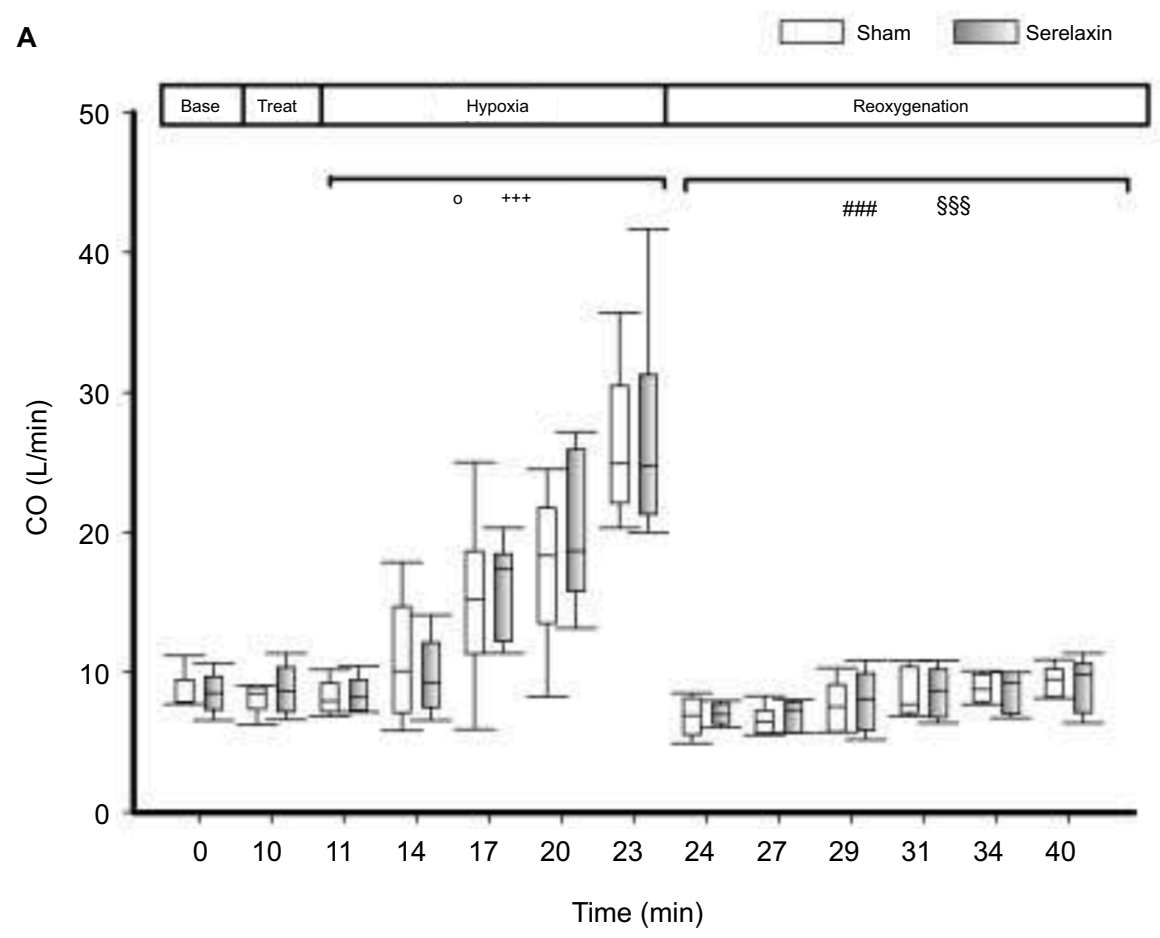

B
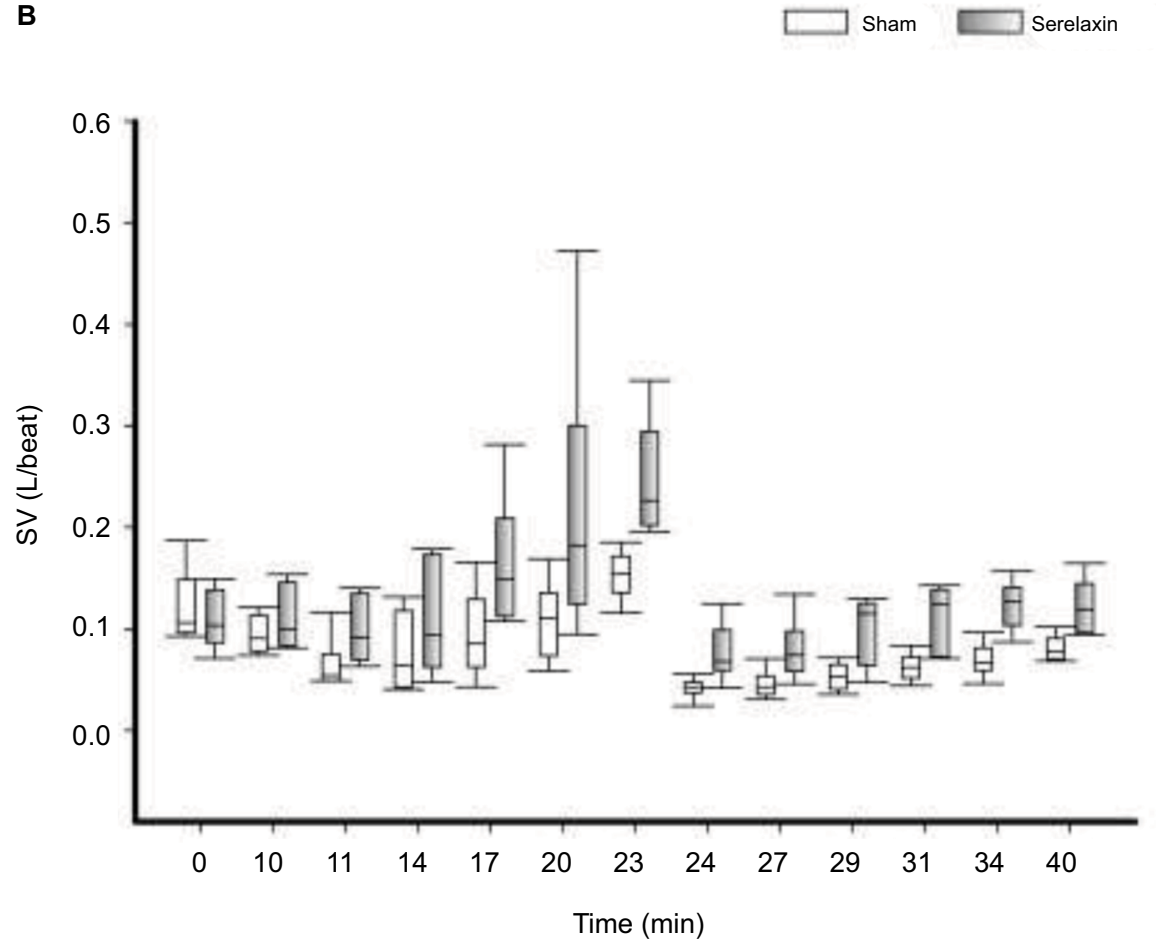

Figure 5 Effects of serelaxin during hypoxia and reoxygenation on cardiac output and stroke volume.

Notes: (A) CO and (B) SV. ${ }^{\circ}, p \leq 0.05$, for comparison of the control group during hypoxia with baseline values.,$+++ p \leq 0.00 \mathrm{I}$, for comparison of the serelaxin-treated group during hypoxia with baseline values. \#\#, $p \leq 0.00 \mathrm{I}$, for comparison of reoxygenation with hypoxia in the control group. $\$ \S \S$, $p \leq 0.00 \mathrm{I}$, for comparison of reoxygenation with hypoxia in the serelaxin-treated group.

Abbreviations: $\mathrm{CO}$, cardiac output; SV, stroke volume.

the detection of low pulmonary hemodynamic responses and furthermore warranted severe physiological response as already successfully applied in preliminary studies..$^{25}$ The applied dosage of $30 \mu \mathrm{g} / \mathrm{kg}$ serelaxin nonetheless does constitute a rather high dosage of serelaxin. While we decided on utilizing this dose both for the reasons stated above and 


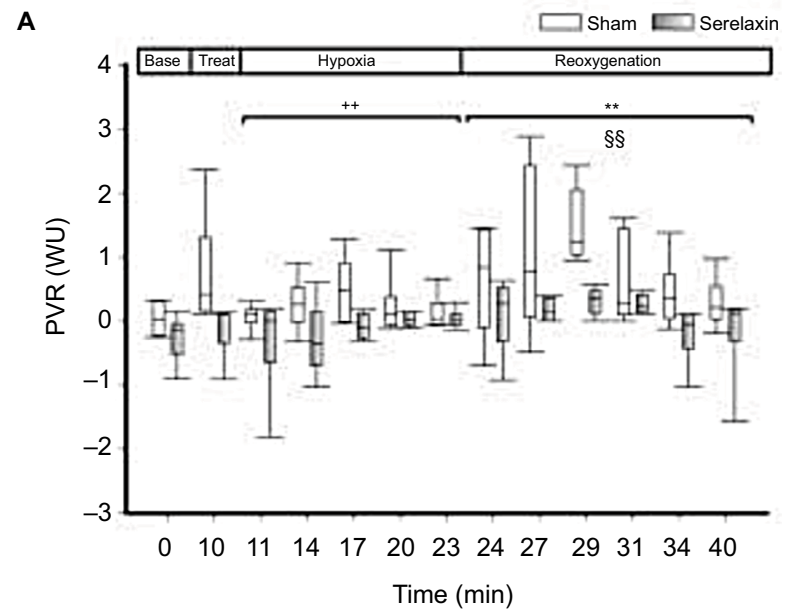

B

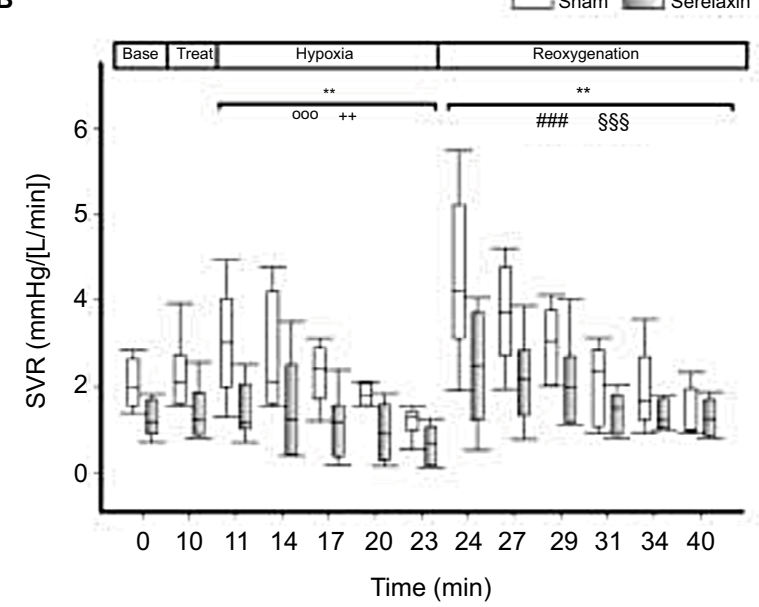

C

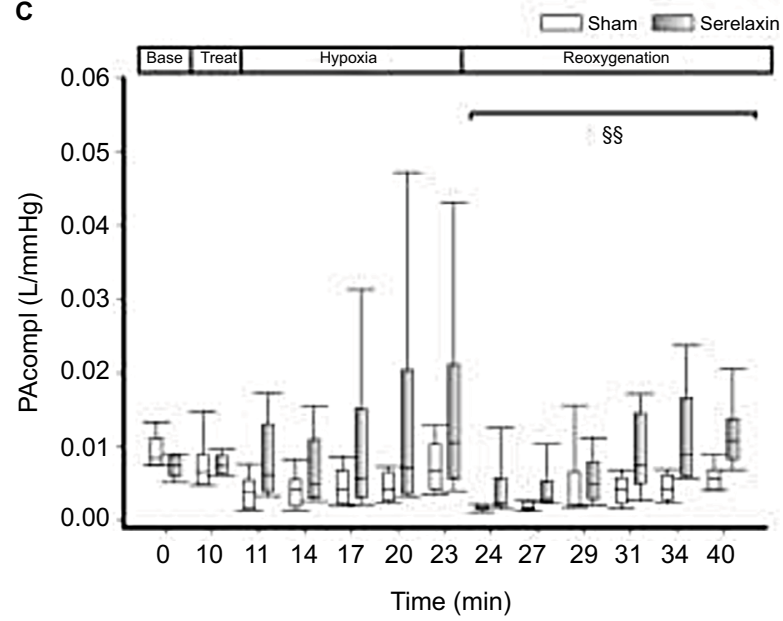

Figure 6 Effects of serelaxin during hypoxia and reoxygenation on pulmonary vascular resistance, systemic vascular resistance, and pulmonary artery compliance. Notes: (A) Pulmonary hemodynamic parameters; PVR, (B) SVR, and (C) PAcompl. **, $p \leq 0.03$, for comparison between the two experimental groups during hypoxia or reoxygenation, respectively. ${ }^{\circ 00}, p \leq 0.001$, for comparison of the control group during hypoxia with baseline values.,$+ p \leq 0.03$, for comparison of the serelaxintreated group during hypoxia with baseline values. \#, $p \leq 0.00 \mathrm{I}$, for comparison of reoxygenation with hypoxia in the control group. $\S \S \S, p \leq 0.00$ I; $\S \S, p \leq 0.03$, for comparison of reoxygenation with hypoxia in the serelaxin-treated group.

Abbreviations: PVR, pulmonary vascular resistance; SVR, systemic vascular resistance; PAcompl, pulmonary artery compliance; WU, Wood's Unit. since we already employed similar experimental models in earlier studies, it represents a potential limitation of this study. Our preliminary studies examined relaxin- 2 concentrations, ${ }^{32}$ relaxin-2 immunoreactivity, and peak relaxin levels, and right hemodynamics after serelaxin administration ${ }^{26}-$ a continued comparability and continuity with these earlier results in the context of dosage and its effects on system physiology seemed therefore desirable. However, in a previous large animal model which investigated the cardioprotective properties of relaxin-2, the maximum effective dosage was $5 \mu \mathrm{g} / \mathrm{kg}$. ${ }^{50}$ Since high dosages of relaxin- 2 can decrease target organ response due to agonist-induced receptor desensitization, ${ }^{51}$ this mechanism was furthermore a likely contributor to the failure of clinical trials with higher dosages. One example of this connection might be a trial on scleroderma patients that utilized dosages of $100 \mu \mathrm{g} / \mathrm{kg},{ }^{52}$ which likely led to a paradoxical disappearance of the desired effect. Therefore, the reported results of this current study might be similarly influenced by the chosen dosage. Future studies should therefore investigate the influence of differing dosages on system physiological alterations and microcirculatory changes of end organs. Most animal and human hypoxic models utilize a $10 \%-12 \%$ oxygen mix, which is already suitable for physiologic response and to observe changes of pulmonary hemodynamics. ${ }^{2-5,53,54}$ Our study model, which utilizes a 5\% air mix, represents deep hypoxic conditions similar to emergency cases, for example, asphyxia or cardiac arrest. ${ }^{55,56}$ We specifically decided on a short observation period of 20 minutes, in order to mimic an emergency medical setting and to explore the validity of serelaxin application in such a setting. Drugs with a short onset of effect (between a few seconds and 30 minutes) are especially needed and preferred in the field of emergency medicine or in medical settings where a hypoxic event is very likely or can be expected to occur. Patients especially at risk of suffering such an event are for example patients suffering from COPD, sleep apnea, or heart failure. Since the half-life period of serelaxin is 6-8 hours, and our experimental setup only allowed for an evaluation of 20 minutes, ${ }^{48}$ subsequent studies are needed to assess longer effects of the substance.

MABP and the blood gas values did not differ between both groups over the course of the observation period, which confirms the validity of the experimental model. The elevated hematocrit values (collected from femoral artery) over the course of the observation period can most likely be traced back to small fluid volume loss during the anesthesia. ${ }^{57,58} \mathrm{An}$ increased HR after a bolus injection of serelaxin has already been described in other studies in humans and sheep. ${ }^{26,59,60}$ 
This represents another possible limitation of this study, since the systemic effects of our treatment might influence the pulmonary hemodynamics via the Frank-Starling mechanism, which enables beat-to-beat adjustments of the $\mathrm{CO}$ in relation to changes of the venous pressure. Nonetheless, an HR-independent examination of hemodynamic parameters is quite difficult, since one of the main effects of relaxin-2 is an increase of HR. ${ }^{61}$

The observed effects of serelaxin on the pulmonary hemodynamics during hypoxia suggest that region-specific control of hemodynamics may be caused by differing relaxinreceptor densities and mechanisms. Earlier studies have noted that the pulmonary vasoconstrictive response to hypoxia is due to a sensor-effector mechanism. ${ }^{62-65}$ This sensory mechanism that causes pulmonary vasoconstriction is hypothesized to reside in the mitochondria. ${ }^{66}$ The main function of the mitochondria is the generation of adenosine triphosphate (ATP). Electron transport from the electron donors, nicotinamide adenine dinucleotide, and flavin adenine dinucleotide occurs along the electron transport chain. The sensor function of mitochondria is a byproduct of the physiological electron flux. ${ }^{67,68}$ Relaxin-2 signaling is very complex and involves multiple pathways..$^{23,69-71}$ Experimental studies have demonstrated direct effects of relaxin- 2 on mitochondrial function, capacitation, acrosome reaction, adenosine monophosphate (AMP) production, and calcium accumulation. ${ }^{72,73}$ The effects on primary AMP and ATP production have been critically discussed..$^{74,75}$ Unfortunately, studies investigating the endothelial cells of the pulmonary vascular tree have currently been performed neither in humans nor in sheep. Another possible explanation for the observed changes of pulmonary hemodynamics during hypoxia and reoxygenation is the notch-1 pathway. We speculate that the effects of the pulmonary hemodynamics we observed can either be traced back to mitochondrial signaling or processes controlled by the notch-1 pathway. The aforementioned effects of serelaxin are likely due to interactions with specific plasma membrane receptors. Relaxin-2 activates pathways, whose signaling is mediated via RXFP1 in endothelial cells ${ }^{69,70,76,77}$ and which are distributed area-specifically. ${ }^{78}$ Improvements of pulmonary hemodynamics are induced through pulmonary vasodilatation via RXFP1 - and ET 1-mediation, ${ }^{35,79}$ and are effected by decreases of right atrial pressure and SVR. ${ }^{34,35}$ The relaxin-2 activated receptors RXFP1 and RXFP $2^{71}$ are involved in the remodeling of right heart and pulmonary vessels. ${ }^{35,79}$ Studies concerning relaxin-2 signaling and RXFP1 and RXFP2 distribution in sheep have not yet been performed. Further investigations of these densities and signaling functions of the above-mentioned receptors are needed concerning the sheep animal model. Rapid effects on the pulmonary tree that can be observed after serelaxin administration during hypoxic states are encompassed by activation of phosphoinositide 3-kinase via $\mathrm{G}_{\beta \gamma}$, activation of protein kinase $\mathrm{B} / \mathrm{Akt}$, phosphorylation of endothelial NO synthase (eNOS), and the release of NO. ${ }^{80}$ Consistent with this hypothesis is that the eNOS/NO pathway has only recently been shown to be crucial for the regulation of PVR. ${ }^{81}$

\section{Conclusion}

The administration of serelaxin prevented hypoxic pulmonary vasoconstriction. Serelaxin might be suitable to improve pulmonary hemodynamics in clinically relevant scenarios during acute hypoxia and reduce the risk of pulmonary hypertension.

\section{Acknowledgments}

We are grateful to Petra Dobermann, Simone Göbel, Dirk Hergt, and Gabriele Grunert for skillful assistance and support. This project was supported by a grant from Novartis Pharma GmbH.

\section{Author contributions}

All authors contributed toward data analysis, drafting and revising the paper and agree to be accountable for all aspects of the work.

\section{Disclosure}

The authors report no conflicts of interest in this work.

\section{References}

1. Zielinski J. Effects of intermittent hypoxia on pulmonary haemodynamics: animal models versus studies in humans. Eur Respir J. 2005;25(1):173-180.

2. Kato M, Staub NC. Response of small pulmonary arteries to unilobar hypoxia and hypercapnia. Circ Res. 1966;19(2):426-440.

3. Bergofsky EH, Haas F, Porcelli R. Determination of the sensitive vascular sites from which hypoxia and hypercapnia elicit rises in pulmonary arterial pressure. Fed Proc. 1968;27(6):1420-1425.

4. Glazier JB, Murray JF. Sites of pulmonary vasomotor reactivity in the dog during alveolar hypoxia and serotonin and histamine infusion. J Clin Invest. 1971;50(12):2550-2558.

5. Shirai M, Sada K, Ninomiya I. Effects of regional alveolar hypoxia and hypercapnia on small pulmonary vessels in cats. J Appl Physiol. 1986;61(2):440-448.

6. Barer GR, Howard P, Shaw JW. Stimulus-response curves for the pulmonary vascular bed to hypoxia and hypercapnia. J Physiol. 1970;211(1): $139-155$.

7. Reeves JT, Wagner WW Jr, McMurtry IF, Grover RF. Physiological effects of high altitude on the pulmonary circulation. Int Rev Physiol. 1979;20:289-310.

8. McGrath JJ, Prochazka J, Pelouch V, Ostadal B. Physiological responses of rats to intermittent high-altitude stress: effects of age. J Appl Physiol. 1973;34(3):289-293. 
9. Nattie EE, Bartlett D Jr, Johnson K. Pulmonary hypertension and right ventricular hypertrophy caused by intermittent hypoxia and hypercapnia in the rat. Am Rev Respir Dis. 1978;118(4):653-658.

10. Fung YC, Liu SQ. Changes of zero-stress state of rat pulmonary arteries in hypoxic hypertension. J Appl Physiol. 1991;70(6):2455-2470.

11. Berthon-Jones M, Sullivan CE. Ventilation and arousal responses to hypercapnia in normal sleeping humans. JAppl Physiol Respir Environ Exerc Physiol. 1984;57(1):59-67.

12. Becker HF, Piper AJ, Flynn WE, et al. Breathing during sleep in patients with nocturnal desaturation. Am J Respir Crit Care Med 1999;159(1):112-118.

13. Chaouat A, Weitzenblum E, Kessler R, et al. Sleep-related $\mathrm{O}_{2}$ desaturation and daytime pulmonary haemodynamics in COPD patients with mild hypoxaemia. Eur Respir J. 1997;10(8):1730-1735.

14. Levi-Valensi P, Weitzenblum E, Rida Z, et al. Sleep-related oxygen desaturation and daytime pulmonary haemodynamics in COPD patients. Eur Respir J. 1992;5(3):301-307.

15. Ponikowski P, Mitrovic V, Ruda M, et al. A randomized, doubleblind, placebo-controlled, multicentre study to assess haemodynamic effects of serelaxin in patients with acute heart failure. Eur Heart $J$ 2014;35(7):431-441.

16. Teerlink JR, Cotter G, Davison BA, et al. Serelaxin, recombinant human relaxin-2, for treatment of acute heart failure (RELAX-AHF) a randomised, placebo-controlled trial. Lancet. 2013;381(9860):29-39.

17. Teerlink JR, Voors AA, Ponikowski P, et al. Serelaxin in addition to standard therapy in acute heart failure: rationale and design of the RELAX-AHF-2 study. Eur J Heart Fail. 2017;19(6):800-809.

18. Top heart-failure contender serelaxin flops. Nat Biotechnol. 2017;35(4):297.

19. Conrad KP, Shroff SG. Effects of relaxin on arterial dilation, remodeling, and mechanical properties. Curr Hypertens Rep. 2011;13(6):409-420.

20. Masini E, Cuzzocrea S, Mazzon E, et al. Protective effects of relaxin in ischemia/reperfusion-induced intestinal injury due to splanchnic artery occlusion. Br J Pharmacol. 2006;148(8):1124-1132.

21. Hernandez AV. Serelaxin: insights into its haemodynamic, biochemical, and clinical effects in acute heart failure. Eur Heart $J$. 2014;35(7):410-412.

22. Sasser JM, Cunningham MW Jr, Baylis C. Serelaxin reduces oxidative stress and asymmetric dimethylarginine in angiotensin II-induced hypertension. Am J Physiol Renal Physiol. 2014;307(12):F1355-F1362.

23. Sarwar M, Samuel CS, Bathgate RA, Stewart DR, Summers RJ. Serelaxin-mediated signal transduction in human vascular cells: bellshaped concentration-response curves reflect differential coupling to G proteins. Br J Pharmacol. 2015;172(4):1005-1019.

24. National Research Council. Guide for the Care and Use of Laboratory Animals. Vol 8. Washington, DC: National Academies Press; 2011.

25. Bischoff S, Schmidt M, Lehmann T, et al. Increase of cortical cerebral blood flow and further cerebral microcirculatory effects of serelaxin in a sheep model. Am J Physiol Heart Circ Physiol. 2016;11(3): H613-H620.

26. Schiffner R, Reiche J, Schmidt M, et al. Pulmonary arterial compliance and pulmonary hemodynamic effects of serelaxin in a sheep model. Clin Hemorheol Microcirc. 2017;66(3):219-229.

27. Stowe CM, Good AL. Estimation of cardiac output in calves and sheep by the dye and Fick oxygen techniques. Am J Physiol. 1960;198:987-990.

28. Yan T, Zhang GX, Li BL, Zhong K, Xu ZY, Han L. Pulmonary artery haemodynamic properties in patients with pulmonary hypertension secondary to rheumatic mitral stenosis. Heart Lung Circ. 2012;21(12):782-786.

29. Debrah DO, Conrad KP, Jeyabalan A, Danielson LA, Shroff SG. Relaxin increases cardiac output and reduces systemic arterial load in hypertensive rats. Hypertension. 2005;46(4):745-750.

30. Motley HL, Cournand A, Werko L, Himmelstein A, Dresdale D. The influence of short periods of induced acute anoxia upon pulmonary artery pressures in man. Am J Physiol. 1947;150(2):315-320.
31. Fisher C, MacLean M, Morecroft I, et al. Is the pregnancy hormone relaxin also a vasodilator peptide secreted by the heart? Circulation. 2002;106(3):292-295.

32. Bischoff SJ, Schmidt M, Lehmann T, et al. Increase of cortical cerebral blood flow and further cerebral microcirculatory effects of serelaxin in a sheep model. Am J Physiol Heart Circ Physiol. 2016;311(3):H613-H620.

33. Conrad KP, Debrah DO, Novak J, Danielson LA, Shroff SG. Relaxin modifies systemic arterial resistance and compliance in conscious, nonpregnant rats. Endocrinology. 2004;145(7):3289-3296.

34. Debrah DO, Novak J, Matthews JE, Ramirez RJ, Shroff SG, Conrad KP. Relaxin is essential for systemic vasodilation and increased global arterial compliance during early pregnancy in conscious rats. Endocrinology. 2006;147(11):5126-5131

35. Dschietzig T, Teichman S, Unemori E, et al. Intravenous recombinant human relaxin in compensated heart failure: a safety, tolerability, and pharmacodynamic trial. J Card Fail. 2009;15(3):182-190.

36. Galie N, Humbert M, Vachiery JL, et al. 2015 ESC/ERS guidelines for the diagnosis and treatment of pulmonary hypertension. Rev Esp Cardiol (Engl Ed). 2016;69(2):177.

37. Naing P, Kuppusamy H, Scalia G, Hillis GS, Playford D. Non-invasive assessment of pulmonary vascular resistance in pulmonary hypertension: current knowledge and future direction. Heart Lung Circ. 2017;26(4):323-330.

38. Harvey LD, Chan SY. Emerging metabolic therapies in pulmonary arterial hypertension. J Clin Med. 2017;6(4):E43.

39. Hilty MP, Muller A, Fluck D, et al. Effect of increased blood flow on pulmonary circulation before and during high altitude acclimatization. High Alt Med Biol. 2016;17(4):305-314.

40. Li J, Liang X, Zhou Y, et al. Role of dynorphin in hypoxic pulmonary hypertension. Eur J Pharmacol. 2016;791:78-84.

41. Pan M, Han Y, Si R, Guo R, Desai A, Makino A. Hypoxia-induced pulmonary hypertension in type 2 diabetic mice. Pulm Circ. 2017;7(1):175-185.

42. Seccombe LM, Chow V, Zhao W, et al. Right heart function during simulated altitude in patients with pulmonary arterial hypertension. Open Heart. 2017;4(1):e000532.

43. Suresh K, Shimoda LA. Lung circulation. Compr Physiol. 2016;6(2): 897-943.

44. Talbot NP, Robbins PA, Dorrington KL. Changes in pulmonary vascular responsiveness to hypoxia. Exp Physiol. 2017;102(11):1561.

45. Tremblay JC, Boulet LM, Tymko MM, Foster GE. Intermittent hypoxia and arterial blood pressure control in humans: role of the peripheral vasculature and carotid baroreflex. Am J Physiol Heart Circ Physiol. 2016;311(3):H699-H706.

46. Huang Y, Hunyor SN, Jiang L, et al. Remodeling of the chronic severely failing ischemic sheep heart after coronary microembolization: functional, energetic, structural, and cellular responses. Am J Physiol Heart Circ Physiol. 2004;286(6):H2141-H2150.

47. Martelli D, Silvani A, McAllen RM, May CN, Ramchandra R. The low frequency power of heart rate variability is neither a measure of cardiac sympathetic tone nor of baroreflex sensitivity. Am J Physiol Heart Circ Physiol. 2014;307(7):H1005-H1012.

48. Dahlke M, Halabi A, Canadi J, Tsubouchi C, Machineni S, Pang Y. Pharmacokinetics of serelaxin in patients with severe renal impairment or end-stage renal disease requiring hemodialysis: a single-dose, open-label, parallel-group study. J Clin Pharmacol. 2016;56(4): 474-483.

49. Kobalava Z, Villevalde S, Kotovskaya Y, et al. Pharmacokinetics of serelaxin in patients with hepatic impairment: a single-dose, open-label, parallel-group study. Br J Clin Pharmacol. 2015;79(6): 937-945.

50. Perna AM, Masini E, Nistri S, et al. Novel drug development opportunity for relaxin in acute myocardial infarction: evidences from a swine model. FASEB J. 2005;19(11):1525-1527. 
51. Kern A, Bryant-Greenwood GD. Characterization of relaxin receptor (RXFP1) desensitization and internalization in primary human decidual cells and RXFP1-transfected HEK293 cells. Endocrinology. 2009;150(5):2419-2428.

52. Seibold JR, Korn JH, Simms R, et al. Recombinant human relaxin in the treatment of scleroderma. A randomized, double-blind, placebocontrolled trial. Ann Intern Med. 2000;132(11):871-879.

53. Naeije R, Huez S, Lamotte $M$, et al. Pulmonary artery pressure limits exercise capacity at high altitude. Eur Respir J. 2010;36(5): 1049-1055.

54. Kawecki D, Wojciechowska C, Jachec W, et al. The influence of obstructive sleep breathing disturbances on echocardiographic and pulmonary haemodynamic parameters in patients with dilated cardiomyopathy. Kardiol Pol. 2016;74(2):135-141.

55. Liu J, Wang Y, Zhuang Q, et al. Protective effects of cyclosporine A and hypothermia on neuronal mitochondria in a rat asphyxial cardiac arrest model. Am J Emerg Med. 2016;34(6):1080-1085.

56. Newquist MJ, Sobel RM. Traumatic asphyxia: an indicator of significant pulmonary injury. Am J Emerg Med. 1990;8(3):212-215.

57. Brauer KI, Svensen C, Hahn RG, Traber LD, Prough DS. Volume kinetic analysis of the distribution of $0.9 \%$ saline in conscious versus isoflurane-anesthetized sheep. Anesthesiology. 2002;96(2): 442-449.

58. Funes FJ, Granados Mdel M, Morgaz J, et al. Anaesthetic and cardiorespiratory effects of a constant rate infusion of fentanyl in isofluraneanaesthetized sheep. Vet Anaesth Analg. 2015;42(2):157-164.

59. Metra M, Cotter G, Davison BA, et al. Effect of serelaxin on cardiac, renal, and hepatic biomarkers in the Relaxin in Acute Heart Failure (RELAX-AHF) development program: correlation with outcomes. J Am Coll Cardiol. 2013;61(2):196-206.

60. Filippatos G, Teerlink JR, Farmakis D, et al. Serelaxin in acute heart failure patients with preserved left ventricular ejection fraction: results from the RELAX-AHF trial. Eur Heart J. 2014;35(16):1041-1050.

61. Sequeira V, van der Velden J. The Frank-Starling law: a jigsaw of titin proportions. Biophys Rev. 2017;9(3):259-267.

62. Archer SL, Weir EK, Wilkins MR. Basic science of pulmonary arterial hypertension for clinicians: new concepts and experimental therapies. Circulation. 2010;121(18):2045-2066.

63. Archer SL, Will JA, Weir EK. Redox status in the control of pulmonary vascular tone. Herz. 1986;11(3):127-141.

64. Rounds S, McMurtry IF. Inhibitors of oxidative ATP production cause transient vasoconstriction and block subsequent pressor responses in rat lungs. Circ Res. 1981;48(3):393-400.

65. Weir EK, Archer SL. The mechanism of acute hypoxic pulmonary vasoconstriction: the tale of two channels. FASEB J. 1995;9(2):183-189.

66. Hong Z, Kutty S, Toth PT, et al. Role of dynamin-related protein 1 (Drp1)-mediated mitochondrial fission in oxygen sensing and constriction of the ductus arteriosus. Circ Res. 2013;112(5):802-815.

67. Dunham-Snary KJ, Wu D, Sykes EA, et al. Hypoxic pulmonary vasoconstriction: from molecular mechanisms to medicine. Chest. 2017;151(1):181-192.
68. Sylvester JT, Shimoda LA, Aaronson PI, Ward JP. Hypoxic pulmonary vasoconstriction. Physiol Rev. 2012;92(1):367-520.

69. Dschietzig T, Bartsch C, Richter C, Laule M, Baumann G, Stangl K. Relaxin, a pregnancy hormone, is a functional endothelin-1 antagonist: attenuation of endothelin-1-mediated vasoconstriction by stimulation of endothelin type-B receptor expression via ERK-1/2 and nuclear factor-kappa B. Circ Res. 2003;92(1):32-40.

70. Dschietzig T, Richter C, Bartsch C, et al. The pregnancy hormone relaxin is a player in human heart failure. FASEB J. 2001;15(12):2187-2195.

71. Bathgate RA, Halls ML, van der Westhuizen ET, Callander GE, Kocan M, Summers RJ. Relaxin family peptides and their receptors. Physiol Rev. 2013;93(1):405-480.

72. Miah AG, Tareq KM, Hamano K, Kohsaka T, Tsujii H. Effect of relaxin on acrosome reaction and utilization of glucose in boar spermatozoa. J Reprod Dev. 2006;52(6):773-779.

73. Ferlin A, Menegazzo M, Gianesello L, Selice R, Foresta C. Effect of relaxin on human sperm functions. J Androl. 2012;33(3):474-482.

74. Colon JM, Ginsburg F, Lessing JB, et al. The effect of relaxin and prostaglandin E2 on the motility of human spermatozoa. Fertil Steril. 1986;46(6):1133-1139.

75. Feugang JM, Rodriguez-Munoz JC, Dillard DS, Crenshaw MA, Willard ST, Ryan PL. Beneficial effects of relaxin on motility characteristics of stored boar spermatozoa. Reprod Biol Endocrinol. 2015;13:24.

76. Dschietzig T, Richter C, Bartsch C, et al. Flow-induced pressure differentially regulates endothelin-1, urotensin II, adrenomedullin, and relaxin in pulmonary vascular endothelium. Biochem Biophys Res Commun. 2001;289(1):245-251.

77. Jeyabalan A, Novak J, Danielson LA, Kerchner LJ, Opett SL, Conrad KP. Essential role for vascular gelatinase activity in relaxin-induced renal vasodilation, hyperfiltration, and reduced myogenic reactivity of small arteries. Circ Res. 2003;93(12):1249-1257.

78. Jelinic M, Leo CH, Post Uiterweer ED, et al. Localization of relaxin receptors in arteries and veins, and region-specific increases in compliance and bradykinin-mediated relaxation after in vivo serelaxin treatment. FASEB J. 2014;28(1):275-287.

79. Stangl K, Dschietzig T, Richter C, et al. Pulmonary release and coronary and peripheral consumption of big endothelin and endothelin-1 in severe heart failure: acute effects of vasodilator therapy. Circulation. 2000;102(10):1132-1138.

80. Halls ML, Bathgate RA, Sutton SW, Dschietzig TB, Summers RJ. International Union of Basic and Clinical Pharmacology. XCV. Recent advances in the understanding of the pharmacology and biological roles of relaxin family peptide receptors $1-4$, the receptors for relaxin family peptides. Pharmacol Rev. 2015;67(2):389-440.

81. McGuane JT, Danielson LA, Debrah JE, Rubin JP, Novak J, Conrad KP. Angiogenic growth factors are new and essential players in the sustained relaxin vasodilatory pathway in rodents and humans. Hypertension. 2011;57(6):1151-1160.

82. Kilkenny C, Browne W, Cuthill IC, et al. Animal research: reporting in vivo experiments: the ARRIVE guidelines. Br J Pharmacol. 2010;160(7): $1577-1579$
Hypoxia

\section{Publish your work in this journal}

Hypoxia is an international, peer-reviewed, open access journal that aims to improve understanding of the biological response to hypoxia. The journal will publish original research articles, reviews, methodological advances, clinical studies, and expert opinions that identify developments in the regulation of the physiological and pathological responses to Submit your manuscript here: https://www.dovepress.com/hypoxia-journal

\section{Dovepress}

hypoxia and in the therapeutic targeting of hypoxia-responsive pathways. The manuscript management system is completely online and includes a very quick and fair peer-review system, which is all easy to use. Visit http://www.dovepress.com/testimonials.php to read real quotes from published authors. 